\title{
Evaluation of Some Renal Function Parameters in Rats Treated with Acrylamide
}

\author{
${ }^{1}$ Yeşim YENER, ${ }^{2}$ Fatma Hümeyra YERLIKAYA, ${ }^{2}$ Aysun TOKER \\ ${ }^{1}$ University of Abant İzzet Baysal, Faculty of Education, Department of Primary Education, \\ Gölköy-Bolu/TURKEY \\ yesimyener77@gmail.com \\ ${ }^{2}$ University of Necmettin Erbakan, Meram Faculty of Medicine, Department of Biochemistry, \\ Konya/TURKEY \\ fhumeyray@hotmail.com \\ aysuntoker@gmail.com
}

\begin{abstract}
Acrylamide is a substance occured carbohydrate-rich foods during cooking high temperature and because of its small and hydrophilic structure, it can diffuses easily throughout the body. Due to this reason all tissues teorically become the target according to the acrylamide toxicity. In this study it was investigated whether acrylamide has any effect on the renal function of the male and female rats receiving long term acrylamide. In total, 25 male and 25 female Wistar rats were involved in this experiment. Animals in each sex were segregated into three groups. Two of them were treatment groups and one of them was control group. Each treatment group consisted of ten animals and each control group consisted of five animals. Acrylamide was administered to the treatment groups at 2 and $5 \mathrm{mg} / \mathrm{kg} / \mathrm{bw} /$ day via drinking water for 90 days. At the end of the experiment, plasma samples were analyzed for sodium, potassium, chlor, calcium, phosphor, urea, uric acid and creatinine levels with the spectrophotometric method. At the end of the study it was observed that serum urea and creatinin levels statistically increased in the male and female rats just treated with $5 \mathrm{mg} / \mathrm{kg} / \mathrm{bw} / \mathrm{day}$ acrylamide $(p<0.05)$ when compared to the rats treated with $2 \mathrm{mg} / \mathrm{kg} / \mathrm{bw} /$ day acrylamide and control groups. Besides this there was no statistically difference serum sodium, potassium, chlor, calcium, phosphor and uric acid levels in rats treated with 2 and $5 \mathrm{mg} / \mathrm{kg} / \mathrm{bw} /$ day acrylamide when compared to the control groups $(p>0.05)$. According to the our findings it was possible to say that acrylamide treatment affects negativelly renal function in rats. In parallel with this the finding of acrylamide in most consumed foods such as potato chips may have negative effect on human health.
\end{abstract}

Keywords: Acrylamide, renal function test, urea, creatinin

\section{INTRODUCTION}

Acrylamide, is a substance having a molecular formula as $\mathrm{C}_{3} \mathrm{H}_{5} \mathrm{NO}\left(\mathrm{CH}_{2}=\mathrm{CH}-\mathrm{CONH}_{2}\right)$ and molecular weight of 71.08 which is colorless, odorless, in a crystalline structure and can just be dissolved in polar solvents such as aceton, methanol, ethanol as well as water [1]. Acrylamide polymer (polyacrylamide) is used commonly in various application areas such as drinking and wastewater treatments, paper pulp and paper production, mining and mineral processing, in the composition of various cosmetics products and molecular research laboratories [2]. While people are exposed to acrylamide by dermal or by inhalation exposure because of their jobs, in 2002, some Swedish researchers $[3,4]$ revealed that acrylamide occurred carbohydrate rich foods during cooking at high temperatures and this indicated that this substance might be ingested via foods.

Acrylamide is absorbed very rapidly by digestion system after its inception by humans and animals as well as is distributed to the whole body. Following its absorption, it spreads to many organs such as thymus, liver, heart, brain and kidney [5], moreover, might reach fetus after passing through placental barrier [6]. Its presence was also determined in breast milk [7].

After incoming the body acrylamide either transforms into glycidamide, epoxide metabolite of acrylamide, via oxidation by cytochrome P450 2E1 enzyme [8,9], or conjugates with glutathione 
(GSH) [10]. Epoxidation of equal amounts of acrylamide to glycidamide is 2-4 times less in humans when compared to rodents [11-13]. Toxicokinetic studies in humans indicated that $60 \%$ of absorbed acrylamide is mostly eliminated in urine (86\%) as GSH and just $4.4 \%$ of this incoming acrylamide was unchanged. A small amount of unchanged glycidamide was also determined in human urine [11]. Acrylamide and its metabolites accumulate in blood by combining with hemoglobin. Moreover, it was also stated that they accumulate in nervous system, male reproduction system, liver and kidney [14].

Since acrylamide molecule is small and has hydrophillic structure, this makes it possible for it to reach every organ and so every tissue in the body naturally [8]. For this reason, all tissues are in the target of negative effects of acrylamide theoretically.

Residual products (urea, creatinin, uric acid, etc.) formed as a result of metabolic reaction of any substance incoming the body are removed from the blood by kidneys which are natural treatment system of the body. In addition to this, kidneys can perform many vital functions such as regulation of water balance in the body and protection of body liquids (acidity/alkalinity). Kidneys can filtrate about 200 litres of blood per day and remove toxic materials and excess liquid via 1.5 liter urine. Within this period, any imbalance occurred might cause disorder of kidney functions rapidly [15]. Kidney function disorder is resulted as accumulation of toxic substances in the blood that should be removed from the body [16]. In practice, blood and urine tests are carried out for the assessment of kidney functions and determination of degree and level of function disorders. Such tests indicate to what extent kidneys are successful to filtrate these residual products and excess liquid in the body [17]. Creatinin and blood urine nitrogen (BUN) can be searched in a blood sample. As filtration process of kidneys decreases, the levels of these residual products increase in the blood. Abnormal results obtained are generally first indicators of kidney diseases [18].

In this study it was investigated whether acrylamide has any effect on the renal function of the male and female rats receiving long term acrylamide.

\section{Materials AND Methods}

\subsection{Test Chemical}

Acrylamide (Cas 79-06-1) was received from Sigma Aldrich Chemical Company. The material was a white odourless crystalline solid, with a chemical purity of $>99 \%$ (for electrophoresis). The test material was prepared weekly and stored at room temperature. All other chemicals used were of analytical grade.

\subsection{Dosing}

In our study acrylamide must be given to the rats either with gavage or with drinking water. Our experimental period is too long to give this substance by gavage because of making any degeneration in rats esophagus and the water solubility of acrylamide is very high $\left(2.16 \mathrm{~g} / \mathrm{ml}\right.$ at $\left.30{ }^{\circ} \mathrm{C}\right)$ and there isn't any residue in water. Therefore we prefered to give acrylamide to the rats via drinking water. We decided our acrylamide doses as 2 and $5 \mathrm{mg} / \mathrm{kg} /$ day in our study since not to occure a characteristic sign of acrylamide-induced neurotoxicity such as hindlimb foot splaying [19, 20].

\subsection{Animals and husbandry}

Male and female weaned Wistar rats, weighing 65-75 g and aged 3-4 weeks old, were obtained from Selcuk University Experimental Medicine Research and Application Centre (Konya, Turkey). The rats were housed in wire-topped opaque polycarbonate cages and maintained under constant environmental conditions with a $12 \mathrm{~h}$ light/dark schedule. The environmental temperature was $20 \pm 2$ ${ }^{\circ} \mathrm{C}$ and humidity was 50\%. Commercial food pellets and drinking water were provided by ad libitum. The protocols of the animal experiments were approved by the internal ethical commitee of the University.

\subsection{Experimental design}

In total, 25 male and 25 female Wistar rats were involved in this experiment. Animals in each sex were segregated into three groups. Two of them were treatment groups and one of them was control group. Each treatment group consisted of ten animals and each control group consisted of five animals. Acrylamide was administered to the treatment groups at 2 and $5 \mathrm{mg} / \mathrm{kg} / \mathrm{day}$ via drinking water for 90 days. Tap water was administered to five animals of control group in the same manner as 
in the treatment groups. All animals were sacrificed $24 \mathrm{~h}$ after the last treatment by cervical dislocations under ether anesthesia.

\subsection{Sample analyses}

Cardiac puncture was used to collect blood samples at the indicated sacrifice times. Blood samples were centrifuged at $2500 \mathrm{rpm}$ for $10 \mathrm{~min}$ and serum was taken. Urine and serum sodium, chlorine, calcium, urea, uric acid and creatinin levels were measured using autoanalyser (Synchron LX System (Beckman Coulter, Fullerton CA).

\subsection{Statistical analysis}

All data are expressed as mean \pm standart deviations. Statistical analyses were done using SPSS v. 16.0 (SPSS Inc., IL, USA). Groups of data were compared to an analysis of variance (ANOVA) followed by Tukey's multiple comparison tests. Differences were considered significant at a probability level of $p<0.05$.

\section{RESULTS}

In order to determine its effect on kidney functions of rats, 2 and $5 \mathrm{mg} / \mathrm{kg} /$ day acrylamide was given to male and female rats via drinking water for 90 days and after application the serum samples taken from the rats were investigated in terms of sodium, chloride, calcium, urea, uric acid and creatinin levels whereas urine samples were investigated in terms of calcium and creatinin levels. As a result of these investigations, the findings obtained are given in Table 1. During experiments, any diseases, decrease in activity or mortality were not observed in rats.

According to the results of analysis belonging to the serum of rats, it was observed that there wasn't a statistically significant difference in male and female rats which were applied 2 and $5 \mathrm{mg} / \mathrm{kg} / \mathrm{day}$ acrylamide when sodium, chloride, calcium, urea, uric acid and creatinin levels as well as calcium levels in urine were compared within themselves and with control group $(p>0.05)$. On the other hand, when serum urea and creatinin levels as well as urine creatinin levels of male and female rats which were applied with $5 \mathrm{mg} / \mathrm{kg}$ /day acrylamide were compared with other groups, it was found statistically and significantly higher $(\mathrm{p}<0.05)$.

Table 1. The results of serum and urine parameters of rats in whole groups (All values are mean \pm standart deviation).

\begin{tabular}{|c|c|c|c|c|}
\hline Parameters & Group & Control & $2 \mathrm{mg} / \mathrm{kg} /$ day acrylamide & $5 \mathrm{mg} / \mathrm{kg} /$ day acrylamide \\
\hline \multirow{2}{*}{$\begin{array}{l}\text { Sodium }(\mathrm{Na}) \\
(\mathrm{mEq} / \mathrm{L})\end{array}$} & Male & $1.37 \pm 1.5$ & $1.38 \pm 2.0$ & $1.37 \pm 0.9$ \\
\hline & Female & $1.36 \pm 0.9$ & $1.37 \pm 1.5$ & $1.35 \pm 1.7$ \\
\hline \multirow{2}{*}{$\begin{array}{l}\text { Chlorine (CI) } \\
(\mathrm{mEq} / \mathrm{L})\end{array}$} & Male & $100.0 \pm 1.9$ & $99.1 \pm 2.7$ & $99.6 \pm 1.8$ \\
\hline & Female & $103.0 \pm 1.3$ & $100.1 \pm 1.6$ & $99.8 \pm 1.2$ \\
\hline \multirow{2}{*}{$\begin{array}{l}\text { Calcium }(\mathrm{Ca}) \\
(\mathrm{mg} / \mathrm{dL})\end{array}$} & Male & $10.0 \pm 0.2$ & $10.1 \pm 0.4$ & $10.2 \pm 0.4$ \\
\hline & Female & $10.1 \pm 0.2$ & $10.1 \pm 0.5$ & $10.1 \pm 0.5$ \\
\hline \multirow[t]{2}{*}{ Urea (mg/dL) } & Male & $35.80 \pm 2.6$ & $40.0 \pm 5.9$ & $45.25 \pm 4.9^{\mathrm{a}}$ \\
\hline & Female & $38.75 \pm 1.7$ & $46.20 \pm 6.5$ & $49.0 \pm 4.9^{\mathrm{a}}$ \\
\hline \multirow{2}{*}{$\begin{array}{l}\text { Uric acid } \\
(\mathrm{mg} / \mathrm{dL})\end{array}$} & Male & $0.65 \pm 0.05$ & $1.03 \pm 0.42$ & $1.03 \pm 0.47$ \\
\hline & Female & $0.67 \pm 0.07$ & $0.84 \pm 0.09$ & $1.15 \pm 0.7$ \\
\hline \multirow{2}{*}{$\begin{array}{l}\text { Creatinine } \\
(\mathrm{mg} / \mathrm{dL})\end{array}$} & Male & $0.24 \pm 0.02$ & $0.28 \pm 0.03$ & $0.38 \pm 0.07^{\mathrm{a}}$ \\
\hline & Female & $0.31 \pm 0.02$ & $0.36 \pm 0.07$ & $0.43 \pm 0.09^{\mathrm{a}}$ \\
\hline \multirow{2}{*}{$\begin{array}{l}\text { Urine (Ca) } \\
(\mathrm{mg} / \mathrm{dL})\end{array}$} & Male & $4.70 \pm 2.1$ & $5.42 \pm 2.4$ & $4.71 \pm 1.1$ \\
\hline & Female & $3.56 \pm 1.5$ & $5.90 \pm 2.2$ & $5.40 \pm 2.7$ \\
\hline \multirow{2}{*}{$\begin{array}{l}\text { Urine creatinine } \\
(\mathrm{mg} / \mathrm{dL})\end{array}$} & Male & $12.24 \pm 3.6$ & $18.11 \pm 13.3$ & $28.67 \pm 30.6^{\mathrm{a}}$ \\
\hline & Female & $9.95 \pm 0.1$ & $10.43 \pm 0.9$ & $36.36 \pm 29.4^{\mathrm{a}}$ \\
\hline
\end{tabular}

${ }^{a} \mathrm{p}<0.05$ statistically different group when compared with control group. 


\section{DISCUSSION}

Because of increase and perfusion of concentration of residual products formed as a result of metabolism in kidney tubules, the kidneys are easily injured organs [21]. The levels of urea and creatinin in serum are used as indicators for determination of kidney functions, however, concentration of serum creatinine is a more effective indicator than urea concentration at the initial stages of kidney diseases [22].

In 2002, presence of acrylamide unexpectedly in various food products at high amounts necessitated performing additional experiments in order to determine negative effects of this material on health [23]. In studies carried out to understand formation mechanism of acrylamide in foods, it was determined it formed as a result of Maillard reaction between amino acids (especially asparagine) and sugars during cooking of some foods [3, 4]. As a result of experiments performed with rodents to determine its effects on health, it was stated that acrylamide has different neoplastic effects such as follicular thyroid tumours, scrotal mesothelioma, breast gland tumours, lung carcinoma, glial brain tumours, mouth cavity papillomas and uterine adenocarcinoma both in male and female mice and rats [24-27]. As a result of these assessments, acrylamide is classified as "possible human carcinogen" (Group 2A) by IARC [1]. It was clearly revealed as a result of in vivo and in vitro experiments that acrylamide and its basic metabolite, glycidamide, have genotoxic and clastogenic effects [5, 28-30]. Large intestine, bladder and kidney are the organs that are more target to the acrylamide incoming body via foods because acrylamide and its basic metabolite, glycidamide are detoxified by glutathione conjugation, absorbed rapidly by digestion system after dissolving in water and removed from the body via urine [1].

Since humans are always exposed to low-dosages of acrylamide within their diets, this study was designed to determine how chronic acrylamide intake affects kidney parameters in terms of experimental animal. Therefore, the weaned male and female Wistar rats were applied acrylamide in 2 and $5 \mathrm{mg} / \mathrm{kg} /$ day acrylamide via drinking water for 90 days. The serum samples taken from the rats after application were investigated in terms of sodium, chloride, calcium, urea, uric acid and creatinine levels whereas urine samples were investigated in terms of calcium and creatinine levels. When the data obtained from serum and urine samples were compared with control groups, it was determined that urea and creatinine levels in serum as well as creatinine level in urine increased in both male and female rats just at the highest dosage and a significant difference was not indicated in other serum and urine parameters.

In a study carried out with Sprague-Dawley rats, they were fed by their basic diets mixed with $15 \%$ and $30 \%$ potato chips and toasted bread for 6 weeks. As a result of experiments, it was observed that serum glucose and creatinine levels as well as many biochemical parameters (serum MDA, ALT and AST, total cholesterol, HDL-cholesterol, LDL-cholesterol levels) significantly increased [31]. In another study performed by Abd-El Mottaleb and Rashed [32], 75 and $150 \mathrm{mg} / \mathrm{L}$ (1/20 and 1/10 of acrylamide $\mathrm{LD}_{50}$ dosage) acrylamide were applied to male albino rats in drinking water for 28 days and its toxic effects on brain, thyroid gland, testis, liver and kidney were investigated. As a result of acrylamide toxicity, it was determined that there were variations in some biochemical parameters such as significant decrease in urea concentration, some enzymatic activities (ALT and AST) were inhibited, there was a decrease in testosterone, T3 and T4 hormones, the most affected organs were brain, thyroid gland and testis followed by liver and kidney according to histopathological evaluation. In addition to this, a significant difference was not determined in serum total protein, albumin and creatinine levels. In a study where $50 \mathrm{mg} / \mathrm{kg} /$ day acrylamide dosage was applied to Wistar male rats through oral route for 10 days and the protective effect of selenium was searched against acrylamide toxicity, it was stated that it caused a significant increase in direct bilirubin, total bilirubin, total cholesterol, LDL-cholesterol indicating liver activity as well as creatinine, urea and uric acid indicating kidney activity. It was emphasized that selenium application decreased the increase in parameters and in fact decreased the level of serum creatinine to basal level [33].

In another study, experiments were performed to investigate the effect of acrylamide on its oxidative damage in organs such as kidney, spleen, testis and brain, a diet including 0.34 gram acrylamide per $\mathrm{kg}$ of their consumed diet was applied to male Sprague-Dawley rats for 11 days. Moreover, the effect of garlic powder added in the diets at the rates of $2.5 \%$ and $5 \%$ on acrylamide-sourced oxidative damage was investigated. As a result of the research, it was concluded that applied acrylamide caused oxidative damage in the examined tissues and moreover resulted in a significant increase in LDH 
activity as well as serum urea and creatinine levels. It was indicated that garlic powder application had a protective effect against acrylamide and decreased biochemical variations [34]. A similar study was carried out with Wistar rats and the protective effect of $\mathrm{N}$-acetyl-L-cysteine as an antioxidant agent against acrylamide toxicity formed experimentally was investigated in brain, lung, liver, kidney and testis of rats which were applied with $40 \mathrm{mg} / \mathrm{kg} /$ day acrylamide intraperitoneally. It was determined that oxidative damage occurred by acrylamide in the examined tissues and it caused significant increase in serum creatinine level. It was concluded that the applied antioxidant agent was beneficial against acrylamide toxicity risk and balanced oxidant-antioxidant situation [35]. In another study performed by the same researchers, protective effect of melatonin was searched against acrylamide toxicity. It was found that serum creatinine levels measured to assess the kidney function increased due to acrylamide, however, this increase was prevented in groups which were applied melatonin and moreover oxidative organ damage sourced from acrylamide toxicity was reformed by means of antioxidant properties of melatonin [36].

In the study performed by Rawi et al. [37], $15 \mathrm{mg} / \mathrm{kg} /$ day acrylamide was given to male and female rats through oral route for 28 days and it was resulted that acrylamide caused some variations in serum creatinine, urea and uric acid levels of rats when compared to control group. Moreover, these findings were supported histopathologically and it was determined that some occlusions occurred in cortical blood vessels depending on swelling and degeneration of epithelium cells laying in kidney tubules and continuous acrylamide exposure caused local bleeding between tubules in corticomedullar region.

In these studies which indicated that acrylamide given to rats caused damages in organs such as brain, thyroid gland, spleen, liver, testis and kidney, acrylamide was generally applied at high dosages in short times. In our study the effect of acrylamide on kidney function was assessed and it was determined that serum urea and creatinine levels increased. It was also determined that the same effect observed in other studies might occur at low dosages in long times.

There are many epidemiological studies in literature in which the relationship between acrylamide incoming to humans via various ways and different cancer types was searched [38-41]. In a study which was performed with 371 workers exposed to acrylamide by means of organic dyes, it was determined that the rate of death occurred as a result of especially digestion and respiration system cancers was more than expected [42]. In another study carried out with 8500 workers exposed to acrylamide due to their jobs, it was suggested that there was an increase in thyroid cancer and pancreas cancer depending on the exposure dosage [43].

In a study, the relationship between acrylamide intake in humans depending on the diet and kidney cancer, it was revealed that the kidney function was affected and there was a positive relationship between acrylamide and increase in kidney-cell cancer [44]. Moreover, it was also determined that there was a positive relationship between kidney cancer formation in humans as well as animals and oestrogen hormone [45, 46]. It was indicated that glycidamide, epoxide metabolite of acrylamide, affected regulation of genes catalysing the transformation of inactive androgen and oestrogen precursors to active forms such as testosterone and 17 $\beta$-estradiol [47].

Consequently, it was determined in this study that acrylamide, having some negative effects on health, significantly increased serum urea and creatinine levels of male and female rats at low dosages and for long time intake. Based on this study which indicated the negative effects of acrylamide on some kidney parameters and based on different studies which indicated its negative effects on human beings, it is suggested that a diet in which consumption of foods including this material decreased should be selected and all precautions should be taken.

\section{REFERENCES}

[1] IARC (International Agency for Research on Cancer), Acrylamide, IARC Monographs on the evaluation of carcinogenic risk to humans, some industrial chemicals, vol. 60. International Agency for Research on Cancer, Lyon, 60, pp. 389-443 (1994).

[2] European Union Risk Assessment Report: Acrylamide, Luxemburg, 210 p. European Union. (2002).

[3] Mottram D. S., Wedzicha B. L. and Dodson A. T., Acrylamide is formed in the Maillard reaction, Nature, pp. 419, 448 (2002). 
[4] Stadler R. H., Blank I., Vorga N., Robert F., Hav J., Guy P. A., Robert M. C. and Reidiker S., Acrylamide from Maillard reaction products, Nature, pp. 419:449 (2002).

[5] Abramson-Zetterberg L., Wong J. and Ilbäck N. G., Acrylamide tissue distribution and genotoxic effects in a common viral infection in mice, Toxicol., 211, pp. $70-76$ (2005).

[6] Schettgen T., Kütting B., Hornig M., Beckmann M. W., Weiss T., Drexler H., Angerer J., Transplacental exposure of neonates to acrylamide-a pilot study, Int Arch Occup Environ Health, 77, pp. 213-216 (2004).

[7] Sorgel F., Weissenbacher R., Kinzig-Schippers M., Hofmann A., Illauer M., Skott A., Landersdorfer C., Acrylamide: increased concentrations in homemade food and first evidence of its variable absorption from food, variable metabolism and placental and breast milk transfer in humans, Chemotherapy, 48, pp. 267-274 (2002).

[8] Friedman M., Chemistry, biochemistry and safety of acrylamide: a review. J Agric. Food Chem., 51, pp. 4504-4526 (2003).

[9] Sumner S. C. J., Fennell T. R., Moore T. A., Chanas B., Gonzalez F., Ghanayem B. I., Role of cytochrome P450 2E1 in the metabolism of acrylamide and acrylonitrile in mice, Chem. Res. Toxicol., 12, pp. 1111-1116 (1999).

[10] Sumner S. C., Macneela J. P. and Fennell T. R., Characterization and quantitation of urinary metabolites of $\left[1,2,3-{ }^{13} \mathrm{C}\right]$ acrylamide in rats and mice using ${ }^{13} \mathrm{C}$ nuclear magnetic resonance spectroscopy, Chem. Res. Toxicol., 5, pp. 81-89 (1992).

[11] Fennell T. R., Sumner S. C. J., Snyder R. W., Burgess J., Spicer R., Bridson W. E., Friedman M. A., Metabolism and hemoglobin adduct formation of acrylamide in humans. Toxicol. Sci., 85, pp. 447-459 (2005).

[12] Fennell T. R., Sumner S. C. J., Snyder R. W., Burgess J., Friedman M. A. Kinetics of elimination of urinary metabolites of acrylamide in humans. Toxicol. Sci, 93, pp. 256-267 (2006).

[13] Fuhr U., Boettcher M. I., Kinzig-Schippers M., Weyer A., Jetter A., Lazar A., Taubert D., Tomalik-Scharte D., Pournara P., Jakob V., Harlfinger S., Klaassen T., Berkessel A., Angerer J., Sörgel F., Schömig E., Toxicokinetics of acrylamide in humans after ingestion of a defined dose in a test meal to improve risk assessment for acrylamide carcinogenicity, Cancer Epidemiol. Biomarkers Prev, 15, pp. 266-271 (2006).

[14] Miller M. J., Carter D. E., Sipes I. G., Pharmacokinetics of acrylamide in Fischer-344 rats. Toxicol Appl Pharmacol, 63, pp. 36-44 (1982).

[15] Brenner B. M. and Floyd C. R. Jr., eds. The Kidney, 6th Edition. Philadelphia, PA: W. B. Saunders Company, (1999).

[16] Henry J. B. Clinical Diagnosis and Management by Laboratory Methods, 20th ed. Philadelphia, PA: W. B. Saunders Company, (2001).

[17] Shivaraj G., Prakash B. D., Shruthi S. K., Vinayak V. H., Avinash A. K. M. and Sonal N. V., Markers of renal function tests. N Am J Med Sci. 2(4) pp. 170-173 (2010).

[18] Mehta R. L., Chertow G. M., Acute renal failure definitions and classification: time for change. J Am Soc Nephrol. 14 pp. 2178-2187 (2003).

[19] Burek J. D., Albee R. R., Beyer J. E., Bell T. J., Carreon R. M., Morden D. C., Wade C. E., Hermann E. A., Gorzinski S. J., Subchronic toxicity of acrylamide administered to rats in drinking water follewed by up to 144 days of recovery. J. Environ. Pathol. Toxicol. Oncol. 4, pp. 157-182 (1980).

[20] Smith M. K., Zenick H., Preston R. J., George E. L., Long R. E.,. Dominant lethal effects of subchronic acrylamide administration in the male Long-Evans rat. Mutat. Res. 173, pp. 273-277 (1986).

[21] Mohamed M., Abdellatif M. D., Sabar A., Elglammal M. D., Sodium fluoride ion and renal function after prolonged sevoflurane or isoflurane anaesthesia. Eng. J. Anaesth. 19, pp. 78-83 (2003).

[22] Donadio C., Lucchesi A., Tramonti G., Bianchi C., Creatinine clearance predicted from body cell mass is a good indicator of renal function. Kidney Int. Suppl. 63, pp. 166-168 (1997).

[23] World Health Organization, Additional research on acrylamide in food essential, scientists declare. Geneva, June 2002. Website: http://www.who.int/inf/en/pr-2002-51.html. (2002) 
[24] Bull R. J., Robinson M., Laurie R. D., Stoner G. D., Greisiger E., Meier J. R., Stober J., Carcinogenic effects of acrylamide in Sencar and A/J mice, Cancer Res 44, pp. 107-111 (1984).

[25] Johnson K. A., Gorzinski S. J., Bodner K. M., Campbell R., Wolf C., Friedman M., Mast R., Chronic toxicity and oncogenicity study on acrylamide incorporated in the drinking water of Fischer 344 rats, Toxicol Appl Pharmacol, 85, pp. 154-168 (1986).

[26] Friedman M. A., Dulak L. H. and Stedham M. A., A lifetime oncogenicity study in rats with acrylamide. Fundam Appl Toxicol, 27, pp. 95-105 (1995).

[27] Rice J. M., The carcinogenicity of acrylamide, Mutat Res, 580, pp. 3-20 (2005).

[28] Manjanatha M. G., Aidoo A., Shelton S. D., Bishop M. E., McDaniel L. P., Lyn-Cook L. E. and Doerge D. R., Genotoxicity of acrylamide and its metabolite glycidamide administered in drinking water to male and female Big Blue mice, Environ Mol Mutagen, 47, pp. 6-17 (2006).

[29] Davis J., Recio L., Determination of a micronuclei frequency peripheral blood of B6C3F1 mice exposed acrylamide for four weeks, ILS Report C155-01 (2007).

[30] Yener Y. and Dikmenli M., Increased micronucleus frequency in rat bone marrow after acrylamide treatment. Food Chem Toxicol, 47(8), pp. 2120-2123 (2009).

[31] Khalil F. A. and Abd El Aziem B. H., Effect of dietary acrylamide formed in potato crisps and toasted bread on rats. Egy J Nat Toxins, 2, pp. 57-70 (2005).

[32] Abd El-Mottaleb E. M., Rashed A. Y. M., Some studies on acrylamide intoxication in male albino rats. Egy. J. Comp. Path. \& Clinic. Path., 21(4), pp. 222-245 (2008).

[33] Teodor V., Cuciureanu M., Slencu B. G., Zamosteanu N., Cucireanu R., Potential protective role of selenium in acrylamide intoxication. A biochemical study. Studia Universitatis "Vasile Goldiş”, Seria Ştiintele Vietii, 21(2), pp. 263-268 (2011).

[34] Abd El-Halim S. S. and Mohamed M. M., Garlic powder attenuates acrylamide-induced oxidative damage in multiple organs in rat. J Appl Sci Res, 8(1), pp. 168-173 (2012).

[35] Alturfan E. I., Beceren A., Şehirli A. Ö., Demiralp Z. E., Şener G., Omurtag G. Z., Protective eff ect of $\mathrm{N}$-acetyl-L-cysteine against acrylamide-induced oxidative stress in rats, Turk. J. Vet. Anim. Sci. 36(4), pp. 438-445 (2012).

[36] Tozan-Beceren A., Şehirli A. Ö., Eksioglu-Demiralp E., Şener G., Omurtag G. Z., Melatonin protects against acrylamide induced oxidative tissue damage in rats, Marmara Pharma J, 16, pp. 213-221 (2012).

[37] Rawi S. M., Marie M. A. S., Fahmy S. R., El-Abied S. A., Hazardous effects of acrylamide on immature male and female rats, Afr J Pharm Pharmacol, 6(18), pp. 1367-1386 (2012).

[38] Pelucchi C, Galeone C, Levi F, Negri E, Franceschi S, Talamini R, Bosetti CN, Giacosa A, La Vecchia C. Dietary acrylamide and human cancer. Int J Cancer, 118, pp. 467-71 (2006).

[39] Mucci L. A, Dickman P. W, Steineck G, Adami H. O, Augustsson K., Dietary acrylamide and cancer of the large bowel, kidney, and bladder: absence of an association in a population-based study in Sweden, Br J Cancer 88, pp. 84 -89 (2003).

[40] Mucci L. A, Lindblad P., Steineck G., Adami H. O., Dietary acrylamide and risk of renal cell cancer, Int J Cancer, 109, pp. 774-776 (2004).

[41] Hogervorst J. G, Schouten L. J, Konings E. J, Goldbohm R. A, Van den Brandt P. A. A prospective study of dietary acrylamide intake and the risk of endometrial, ovarian and breast cancer, Cancer Epidemiol Biomarkers Prev;16, pp. 2304 -2313 (2007).

[42] Sobel W., Bond G. G, Parsons T. W., Brenner F. E., Acrylamide cohort mortality study. Br J Ind Med 43, pp. 785-788 (1986).

[43] Marsh G. M., Lucas L. J., Youk A. O., Schall L. C., Mortality patterns among workers exposed to acrylamide: 1994 follow up. Occup Environ Med, 56, pp. 181-190 (1999).

[44] Hogervorst J. G., Schouten L. J., Konings E. J., Goldbohm R. A. and Van den Brandt V. A., Dietary acrylamide intake and the risk of renal cell, bladder, and prostate cancer. Am. J Clin Nutr, 87, pp. $1428-38$ (2008).

[45] Nicodemus K. K., Sweeney C., Folsom A. R., Evolution of dietary, medical and lifestyle risk factors for incident kidney cancer in postmenopausal women. Int J Cancer, 108, pp. 115-21 (2004). 
[46] Tanaka Y., Sasaki M., Kaneuchi M., Fujimoto S., Dahiya R., Estrogen receptor alpha polymorphisms and renal cell carcinoma-a possible risk. Moll Cell Endocrinol, 202, pp. 109-116 (2003).

[47] Clement F. C., Dip R., Naegeli H., Expression profile of human cells in culture exposed to glycidamide, a reactive metabolite of the heat-induced food carcinogen acrylamide. Toxicol, 240, pp. 111-24 (2007). 